\title{
Development and Evaluation of In-Situ Gel Containing Ornidazole Loaded Microspheres for Treatment of Periodontitis
}

\author{
Remeth Jacky Dias ${ }^{a}$, Vijay Daulatrao Havaldar ${ }^{a^{*}}$, Vishwajeet Sampatrao Ghorpade ${ }^{\mathrm{a}}$, Kailas Krishant Mali ${ }^{\mathrm{a}}$, Vaishali \\ Kondibahu Gaikwad ${ }^{\mathrm{b}}$, Dilip Madhukar Kumbhar ${ }^{\mathrm{a}}$ \\ ${ }^{a}$ Department of Pharmaceutics, Yashoda Technical Campus, NH-4, Wadhe, Satara, 415011, MS, India. \\ ${ }^{\mathrm{b}}$ Rajgad Dnyanpeeth's College of Pharmacy, Bhor, MS, India.
}

\begin{tabular}{l}
\hline ARTICLE INFO \\
\hline Article history: \\
Received on: 08/07/2016 \\
Revised on: $19 / 08 / 2016$ \\
Accepted on: 04/09/2016 \\
Available online: $29 / 10 / 2016$ \\
\hline Key words: \\
Chitosan; In-situ gel; \\
Microspheres; Ornidazole; \\
Periodontal disease.
\end{tabular}

\begin{abstract}
The present investigation aims at developing novel injectable in-situ gel containing ornidazole (ORDZ) loaded chitosan microspheres for treatment of periodontal disease. Microspheres were prepared by emulsificationionotropic gelation method. Prepared microspheres were evaluated extensively for particle size, equilibrium swelling studies, bioadhesion, percentage drug release and antimicrobial activity. The mean diameter of the microspheres was found in the range of 29.1-52.65 $\mu \mathrm{m}$. The microspheres showed good swelling properties. Percentage equilibrium swelling was dependent upon the amount of chitosan. The in vitro drug release and bioadhesion studies were dependent on the extent of crosslinking and chitosan concentration. The ORDZloaded microspheres showed drug encapsulation in the range of $11.02 \pm 0.98-32.45 \pm 0.62 \%$ and sustained the release up to 5 days. The drug release from microspheres was diffusion controlled. The antimicrobial study indicated inhibition of growth of Staphylococcus aureus at all drug concentrations of in vitro release samples. In situ gel containing optimized microspheres extended the drug release up to 7 days. Results of the study demonstrated good bioadhesion of the in-situ gel containing microspheres as well as exhibited sustained release of drug. The in-situ gel containing ORDZ- loaded chitosan microspheres may be an efficient alternative to the other known delivery systems for treatment of Periodontitis.
\end{abstract}

\section{INTRODUCTION}

Periodontal diseases are commonly found in all groups, races and genders. They are recognized as one of the major public health problems (Chandur et al., 2007). They are characterized by a presence of disease-causing bacteria, inflammation of the gums, and loss of bone around the teeth. Periodontitis is collection of inflammatory diseases affecting the tissues that surround and support the teeth. It involves progressive loss of the bone around teeth which may lead to loosening and eventual loss of teeth, if untreated (Rahman et al., 2003). Systemic administration of antibiotics have shown

* Corresponding Author

Email:vdh2006@ rediffmail.com several drawbacks including inadequate antibiotic concentration at the site of the periodontal pocket, a rapid decline of the plasma antibiotic concentration to sub-therapeutic levels, the development of microbial resistance and high peak-plasma antibiotic concentrations which may be associated with various side effects. These obvious disadvantages have evoked an interest in the development of novel intra-pocket drug delivery systems for the treatment of periodontal diseases (Govender et al., 2005). The periodontal pocket provides a natural reservoir, which is easily accessible for the insertion of a delivery device. The gingival crevicular fluid (GCF) provides a leaching medium for the release of a drug from the dosage form and for its distribution throughout the pocket. These features, together with the fact that the periodontal diseases are localized to the immediate environment of the pocket, make the periodontal pocket a natural site for treatment with local delivery systems (Goodson et al., 1979). 
The intra-pocket delivery systems investigated so far are fibers (Sachdeva \& Agarwal, 2011), strips (Tariq et al., 2012), films (Gulzar et al., 2009), gels (Rajashree et al., 2009), microparticles (Pichayakorn \& Boonme, 2013), nanoparticles (Piñón-Segundo et al., 2005) and vesicular (Vyas et al., 2001) systems. Fibers, strips and films used for intra-pocket delivery have limited acceptance because of intricacies of winding them into place, the need to retain these devices within the pocket and then their removal after seven to ten days (Jain et al., 2008). Although the microspheres can overcome the problems associated with fibres, films and strips, they have to be dispersed into the saline prior to their administration. Such dispersion may ooze out of the pocket after administration. On other hand, plain gels cannot give the controlled release and have limited bioadhesive property (Park et al., 2005)

Therefore, it is hypothesized that the bioadhesive microspheres containing thermoreversible gels could be effective in such situation. Chitosan is one of the widely used natural polymers in pharmaceutical industry. It is a polysaccharide composed of copolymers of glucosamine and $\mathrm{N}$-acetylglucosamine (Kumar et al., 2004). It is a biocompatible, biodegradable and mucoadhesive polymer of low toxicity suitable for microparticle based drug delivery systems (Nair et al., 2009; Suresh \& Dewangan, 2011).

Till date, the chitosan microparticles of many drugs have been prepared by the researchers in order to achieve bioadhesion and controlled release (Suresh \& Dewangan, 2011; Pichayakorn \& Boonme, 2013; Asane et al., 2011; Swamy et al., 2013). Govender et al., (2005) have reported the application of chitosan microspheres for delivery of tetracycline to the periodontal pocket for treatment of periodontitis. However, the use of thermoreversible gels containing drug loaded chitosan microspheres for intrapocket delivery in periodontitis has not been explored. Pluronic flake 127 (a nonionic surfactant) solutions are known to exhibit the phenomenon of reverse thermal gelation. At low temperatures they remain as solutions and gel when the temperature is increased (Park et al., 2003). This phenomenon may be helpful to retain the microspheres within the pocket for longer duration.

Ornidazole (ORDZ) is chemically 1-chloro-3-(2-methyl5-nitro-1H-imidazol-1-yl) propan-2-ol. It is used in the treatment of hepatic and intestinal amoebiasis, giardiasis, trichomoniasis of urogenital tract and bacterial vaginosis. It is also used in the treatment and prophylaxis of susceptible anaerobic infections in dental and gastrointestinal surgery and in other mixed aerobicanaerobic infections (Sweetman, 2005; Neil et al., 2006).

Recent clinical studies suggest that ORDZ is effective systemically as well as locally for periodontitis (Patel et al., 2014; Patil et al., 2013). As periodontal disease is an infectious disease caused by several pathogenic anaerobic microfloras, ORDZ has been used for the local delivery in this treatment (Park et al., 2005). In present work, an attempt was made to formulate in situ gel containing microspheres for easy insertion directly to the site and maintain its stay for longer duration giving controlled release.

\section{MATERIALS AND METHODS}

\section{Materials}

Ornidazole, Chitosan and Pluronic Flake 127 were obtained as a gift sample from Blue-cross Laboratories Ltd., (Nashik, India), Mahtani Chitosan Pvt. Ltd., (Veraval, India) and Cipla Mfg. Division, (Patalganga, India) respectively. Acetic acid, sodium hydroxide, span 80, hexane and petroleum ether were purchased from Loba Chemie (Mumbai, India).

\section{Preparation of ORDZ microspheres}

The microspheres were prepared by emulsification and ionotropic gelation using sodium hydroxide $(\mathrm{NaOH})$ as gelling agent (Lim et al., 1997). The drug was dispersed in a solution containing $40 \mathrm{ml}$ of $2 \% \mathrm{w} / \mathrm{v}$ chitosan in $2.5 \% \mathrm{v} / \mathrm{v}$ aqueous acetic acid (table 1). The solution was dispersed in $200 \mathrm{ml}$ hexane solution containing $2 \%(\mathrm{w} / \mathrm{v})$ span 80 using mechanical stirrer (Remi motors, Mumbai, India) at $2000 \mathrm{rpm}$. The resultant emulsion was stirred for 30 minutes. Fifteen $\mathrm{ml}$ of $2 \mathrm{~N} \mathrm{NaOH}$ was added slowly at the rate of $5 \mathrm{ml} / \mathrm{min}$. Stirring was continued for $2.5 \mathrm{~h}$. The microspheres were separated by filtration, washed with petroleum ether, followed by distilled water and then air dried. To optimize the preparation of microspheres, the formulation variables like drug concentration, polymer concentration, and concentration of crosslinking agent were changed.

Table 1: Formula for different batches of ORDZ-loaded chitosan microspheres.

\begin{tabular}{llllllll}
\hline \multirow{2}{*}{ Formulation Variables } & \multicolumn{7}{c}{ Formulation Code } \\
\cline { 2 - 8 } & $\mathbf{A 1}$ & $\mathbf{A 2}$ & $\mathbf{A 3}$ & B1 & B2 & C1 & C2 \\
\hline ORDZ $(\mathrm{g})$ & 0.8 & 1.6 & 2.4 & 0.8 & 0.8 & 0.8 & 0.8 \\
Chitosan $(\%$ w/v) & 2 & 2 & 2 & 2.5 & 3 & 2 & 2 \\
Sodium hydroxide solution $(\mathrm{N})$ & 2 & 2 & 2 & 2 & 2 & 2.5 & 3 \\
\hline
\end{tabular}

\section{Characterization of ORDZ microspheres Compatibility study}

The prepared microspheres were subjected to compatibility study by infrared spectroscopy (IR) and differential scanning calorimetry (DSC) analysis in order to ensure the unusual interaction between ORDZ and polymers.

\section{Percentage yield}

The yields of production were calculated as the weight percentage of the final product after drying, with respect to the initial amount of drug and chitosan used for preparations (Yadav and Mote, 2008).

\section{Particle size determination}

The particle size of the microspheres was determined using optical microscope (Lawrence and Mayo, Mumbai, India) fitted with an ocular micrometer and a stage micrometer. The particle diameters of more than 300 microspheres were measured randomly by optical microscope. The average particle size was determined by using Edmondson's equation (Sinko and Sing, 1996),

$$
\mathrm{D}_{\text {mean }}=\sum \mathrm{nd} / \sum \mathrm{n}
$$


Where,

$\mathrm{n}=$ number of microspheres observed

$\mathrm{d}=$ mean size range.

\section{Surface morphology}

The surface morphology of the microspheres was studied using scanning electron microscopy (SEM), (JSM-6360, JEOL Ltd., Tokyo, Japan). Microspheres were sprinkled on to double sided tape, sputter coated with platinum and examined under the microscope at $20 \mathrm{kV}$.

\section{Percentage drug encapsulation}

The encapsulation was determined by taking known quantity of microspheres $(50 \mathrm{mg}$ ) in $50 \mathrm{ml}$ volumetric flask. Sufficient quantity of isotonic phosphate buffered saline (IPBS) $\mathrm{pH} 7.2$ was added to make volume. The suspension was shaken vigorously for $15 \mathrm{~min}$ and then left for $24 \mathrm{~h}$ at room temperature with intermittent shaking. The resultant solution was filtered, diluted with IPBS and ORDZ concentration in the samples was determined by using UV visible spectrophotometer at $318.5 \mathrm{~nm}$ (Patel DM et al., 2012). Efficiency of drug entrapment for each batch was calculated in the term of percentage drug entrapment (PDE) as per the following formula (Dias et al., 2015),

$$
\% \text { Drug entrapment }(\mathrm{PDE})=\frac{\text { Actual drug content }}{\text { Theoretical drug content }} \times 100
$$

\section{Equilibrium swelling studies}

The water absorption capacity of chitosan microspheres was determined using the earlier reported method (Mi et al., 1997). One hundred milligrams of the microsphere sample was placed in $25 \mathrm{ml}$ water for $2.5 \mathrm{~h}$. The microspheres were filtered, blotted with filter paper to remove excess water on the surface and weighed immediately on an electronic balance (Adventurer ${ }^{\mathrm{TM}}$ Ohaus, NJ, USA). Percent swelling of microspheres at equilibrium was calculated as;

$$
E_{S W}=\frac{W_{e}-W_{0}}{W_{0}} \times 100
$$

Where,

$\mathrm{E}_{\mathrm{sw}}=$ the percent swelling of microspheres at equilibrium

$\mathrm{W}_{\mathrm{e}}=$ the weight of microspheres at equilibrium swelling

$\mathrm{W}_{0}=$ the initial weight of microspheres.

\section{In vitro bioadhesion}

The in vitro bioadhesion of microspheres was determined using earlier method (Ranga Rao and Buri, 1989) with certain modification. Microspheres $(50 \mathrm{mg}$ ) were placed on sheep cheek membrane $(2 \mathrm{~cm})$ and kept for $20 \mathrm{~min}$ in a humidity temperature control cabinet (Remi Instruments, Mumbai, India) at $75 \%$ relative humidity and temperature of $25 \pm 2{ }^{\circ} \mathrm{C}$ to allow hydration of the microspheres. This was followed by thorough washing of the mucosal lumen with isotonic phosphate buffered saline $\mathrm{pH}$ 7.2. The washings were then dried at $70^{\circ} \mathrm{C}$ in a hot air oven and weighed. Percent bioadhesion was determined by the following formula:

$$
\text { \%bioadhesion }=\frac{W_{0}-W_{d}}{W_{0}} \times 10
$$

Where,

$\mathrm{W}_{0}=$ weight of applied microspheres

$\mathrm{W}_{\mathrm{d}}=$ Weight of detached microspheres.

\section{In vitro drug release}

The in vitro drug release from different batches of microspheres was evaluated in IPBS, $\mathrm{pH}$ 7.2. Microspheres (equivalent to $1 \mathrm{mg}$ drug) were dispersed in $4 \mathrm{ml}$ of IPBS $\mathrm{pH} 7.2$ at $37^{\circ} \mathrm{C}$ and shaken at $3 \mathrm{rpm}$. At predetermined time intervals, the entire buffer medium was withdrawn and replenished with fresh IPBS (pH 7.2). The amount of ORDZ released into the buffer was measured at $318.5 \mathrm{~nm}$ (Chandur et al., 2007; Haerdi-Landerer et al., 2008).

\section{In vitro antimicrobial activity}

In vitro antimicrobial activity was carried out by using Staphylococcus aureus which is one of the isolates usually found in periodontitis patients (Saini et al., 2003). For this purpose, the samples collected from in vitro release study of blank microspheres, drug-loaded microspheres and ORDZ alone were tested against $\mathrm{S}$. aureus, at different time intervals (24, 48, 72, 96 and $120 \mathrm{~h}$ ) (Govender et al., 2005; Mastiholimath et al., 2006). The nutrient agar medium was prepared and sterilized by autoclaving under aseptic condition and transferred to sterile petriplates. After solidification of nutrient agar medium, lawn was made with $0.1 \mathrm{ml}$ microorganism i.e. $\mathrm{S}$. aureus in petri plates. Wells were made at equidistant from one another and the samples collected from in vitro drug release were filled into it. Samples were allowed to diffuse for $1 \mathrm{~h}$ in refrigerator and finally plates were kept for incubation in incubator at $37 \pm 5^{\circ} \mathrm{C}$ for $24 \mathrm{~h}$ (Friedman and Steinberg, 1998).

\section{Statistical analysis}

Statistical analysis of data was performed using one-way ANOVA followed by Dunnett's multiple comparison tests. The $P$ value less than 0.05 were considered statistically significant.

\section{Optimization of thermoreversible PF-127 aqueous solution}

Thermoreversible gel was prepared according to the cold method (Schmolka, 1972). In brief, sufficient quantity of distilled water was cooled to $4^{\circ} \mathrm{C}$ and slowly the known amount of PF-127 $(16-20 \%$, w/v) was added with continuous stirring. The mixture was kept overnight at $4^{\circ} \mathrm{C}$ and immediately gelation temperature was recorded in triplicate. $1 \% \mathrm{w} / \mathrm{v}$ drug equivalent optimized microspheres were dispersed in prepared PF-127 aqueous solutions and gelation temperature was recorded. Finally, the 
concentration of PF-127 in aqueous solution containing optimized microspheres which gave gelation temperature in the range of 25 to $32{ }^{\circ} \mathrm{C}$, was selected.

\section{Preparation of PF-127 aqueous solution containing optimized microspheres}

Sufficient quantity of distilled water was cooled to $4^{\circ} \mathrm{C}$ and slowly the optimized concentration of PF-127 was added with continuous stirring. The mixture was kept overnight at $4^{\circ} \mathrm{C} .1 \%$ w/v drug equivalent optimized microspheres were dispersed in prepared PF-127 aqueous solution. The prepared formulation was immediately subjected to surface $\mathrm{pH}$, gelation temperature, viscosity and bioadhesion within $24 \mathrm{~h}$.

\section{Characterization of in-situ gel containing ORDZ microspheres Gelation temperature}

The gelation temperature of aqueous solution of PF-127 was measured by using procedures reported by Choi et al., 1998 . A $20 \mathrm{ml}$ transparent vial containing $10 \mathrm{~g}$ aqueous solution of PF127 was heated at an increasing rate of $2^{\circ} \mathrm{C} / \mathrm{min}$ with constant speed of $100 \mathrm{rpm}$ on a magnetic stirrer (Remi, Mumbai, India). The temperature at which rotation of bar $(15 \times 6 \mathrm{~mm})$ stopped was taken as the gelation temperature.

\section{Surface $\mathrm{pH}$}

A digital glass electrode $\mathrm{pH}$ meter was used to measure the surface $\mathrm{pH}$. The $\mathrm{pH}$ was noted by bringing the electrode near the surface of the formulation and allowing it to equilibrate for one minute (Bottenberg et al., 1991).

\section{Viscosity measurement}

The viscosities of various formulations were determined by using cone and plate viscometer (Brookfield viscometer, Model Cap $2000+2$, USA). A sample solution of $0.5 \mathrm{ml}$ was applied to the lower plate of the viscometer using glass rod. The viscosity was recorded using spindle no. 3, at speed of $10 \mathrm{rpm}$ with increase in temperature.

\section{Determination of bioadhesive force}

The bioadhesive potential of formulation was determined by measuring the force required to detach the formulation from sheep cheek mucosa by using a modified chemical balance. A section of cheek mucosa was instantly fixed with mucosal side out onto each glass vial using a rubber band. The vials with cheek mucosa were stored at $37^{\circ} \mathrm{C}$ for 10 minutes. Then first vial with a section of mucosa was connected to the balance in inverted position while second vial was placed on a height adjustable pan. Fixed amount of sample was placed onto the tissue mucosa of second vial. The height of second vial was adjusted so that mucosal surfaces of both vials come in intimate contact. Two minutes contact time was given to ensure intimate contact between tissues and the sample. The weight was kept rising in the pan until vials get detached. The bioadhesive force was determined from the minimal weights that detached the tissues from each other. Following formula was used to determine bioadhesive force in dyne $/ \mathrm{cm}^{2}$ (Choi et al., 1998).

$$
\text { Bioadhesive force }\left(\text { dyne } / \mathrm{cm}^{2}\right)=(\mathrm{m}) \times(\mathrm{g} / \mathrm{A}) \text {..(5) }
$$

Where,

$\mathrm{m}=$ Weight required for detachment of two membrane in grams

$\mathrm{g}=$ Acceleration due to gravity $\left(980 \mathrm{~cm}^{2} / \mathrm{s}\right)$

$\mathrm{A}=$ Area of tissue exposed $\left(\mathrm{cm}^{2}\right)$.

\section{In vitro drug release}

Release of drug from gel containing optimized formulation of ORDZ microspheres was studied employing the permeation apparatus. A glass cylinder with both ends open, $10 \mathrm{~cm}$ height, $3.7 \mathrm{~cm}$ outer diameter and $3.1 \mathrm{~cm}$ inner diameter was used as donor compartment. Cellophane membrane was tied to one end of donor compartment. $1 \mathrm{mg}$ drug equivalent formulation was taken in donor compartment and the cell was immersed in a beaker (receptor compartment) containing $40 \mathrm{ml}$ of isotonic phosphate buffered solution (IPBS), $\mathrm{pH}$ 7.2. The cell was immersed to a depth of $1 \mathrm{~cm}$ below the surface of IPBS in the receptor compartment. Receptor compartment was stirred at 100rpm by a magnetic stirrer and temperature was maintained at $37 \pm 1{ }^{\circ} \mathrm{C}$ throughout the study. Aliquots of $5 \mathrm{ml}$ were withdrawn periodically at intervals of 1 day for a period of 7 days. Sink condition was maintained. The amount of drug release was estimated using UV spectrophotometer at $318.5 \mathrm{~nm}$ (Rajashree et al., 2009).

\section{RESULTS AND DISCUSSION}

\section{Characterization of ORDZ microspheres}

\section{Compatibility study}

The IR spectrum of ORDZ shows characteristic absorption peaks at $3174.10 \mathrm{~cm}^{-1}$ (O-H stretching), $3112.94 \mathrm{~cm}^{-1}$ and $3090.98 \mathrm{~cm}^{-1}$ (C-H stretching), $1538.10 \mathrm{~cm}^{-1}$ (asymmetric $\mathrm{NO}_{2}$ stretching), $1363.13 \mathrm{~cm}^{-1}$ and $1271.72 \mathrm{~cm}^{-1}$ (symmetric $\mathrm{NO}_{2}$ stretching), $1149.83 \mathrm{~cm}^{-1}$ (C-O stretching), $829.31 \mathrm{~cm}^{-1}$ (C-N, $\mathrm{NO}_{2}$ stretching). The IR spectrum of chitosan shows prominent peaks at $3390.13 \mathrm{~cm}^{-1}$ (O-H stretching), $2922.15 \mathrm{~cm}^{-1}$ (C-N stretching) and $1654.48 \mathrm{~cm}^{-1}$ (carbonyl, $\mathrm{C}=\mathrm{O}-\mathrm{NHR}$ ). In the formulation, the peaks of ORDZ at 3174.10, 3112.94, 3090.98, 1149.83 and $829.31 \mathrm{~cm}^{-1}$ completely disappeared due to their masking by the corresponding peaks of PF-127 and chitosan. As can be seen from figure 1, the carbonyl peak of chitosan from $1654.48 \mathrm{~cm}^{-1}$ was shifted to $1642.30 \mathrm{~cm}^{-1}$. This may be due to the hydrogen bonding interaction between $-\mathrm{OH}$ group of ORDZ and Carbonyl group of chitosan. These differences were due to the interactions taking place between the carbonyl group of chitosan with the nitro group of ORDZ (Papageorgiou et al., 2009). 


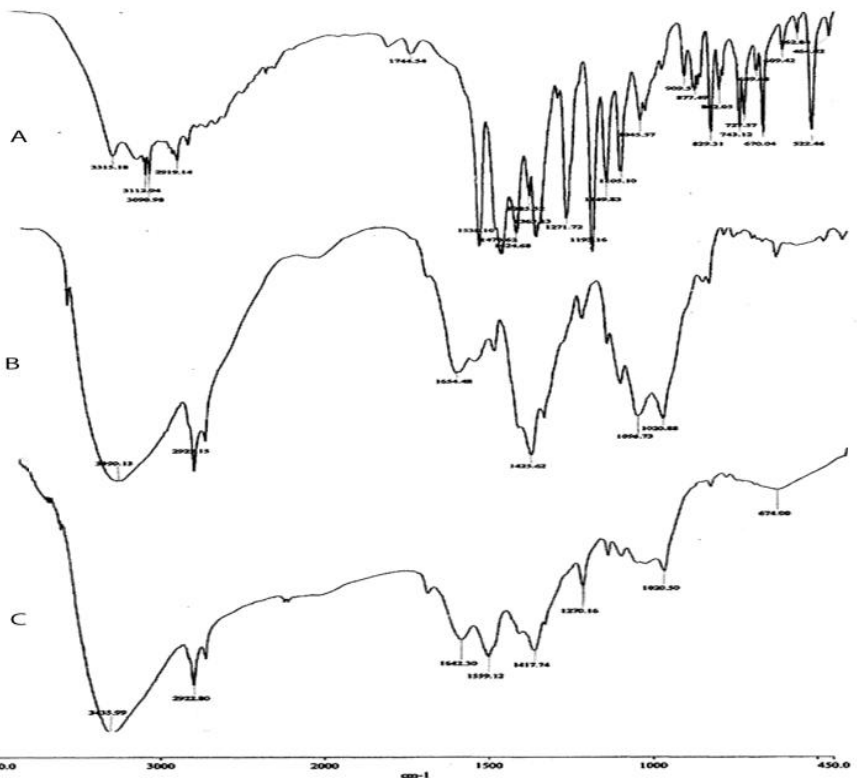

Fig. 1: IR analysis of ORDZ (A), chitosan (B) and drug loaded chitosan microspheres (C)

The DSC thermogram of physical mixture of drug and polymer showed intensity of peak at $87.29^{\circ} \mathrm{C}$ which represents characteristic endothermic peak of pure $\mathrm{ORDZ}$ at $86.66^{\circ} \mathrm{C}$, which is equivalent to the melting point of ORDZ (figure 2). The examination of thermogram of drug loaded microspheres revealed disappearance of ORDZ endothermic peak which indicates molecular dispersion of drug in microspheres (Dias et al., 2015). The overall results of the compatibility study indicated lack of unusual interactions between drug and excipients.
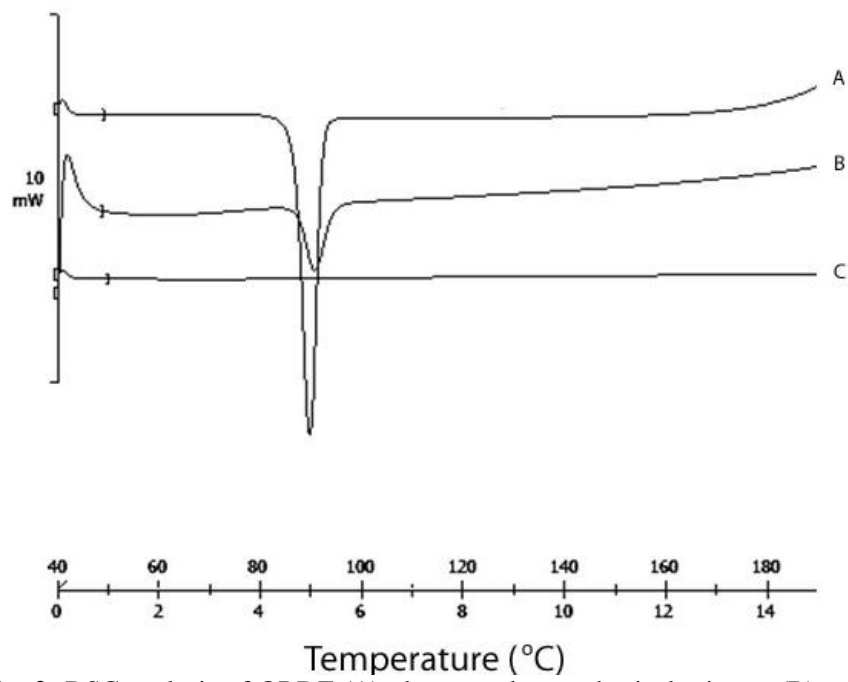

Fig. 2: DSC analysis of ORDZ (A), drug + polymer physical mixture (B) and drug loaded chitosan microspheres (C).

\section{Morphology, yield and size distribution}

The SEM analysis revealed that the formulated microspheres exhibited spherical shape before drug loading. Drug loading led to the formation of irregular microspheres with rough surface. This may be due to presence of pores on surface due to entrapment of drug. The surface roughness of the microspheres was found to be increased with increase in drug concentration. A microphotograph of blank and drug loaded microsphere is shown in figure 3.

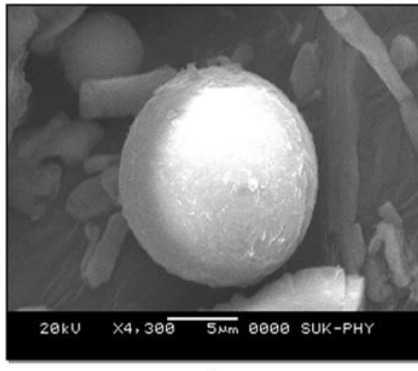

A

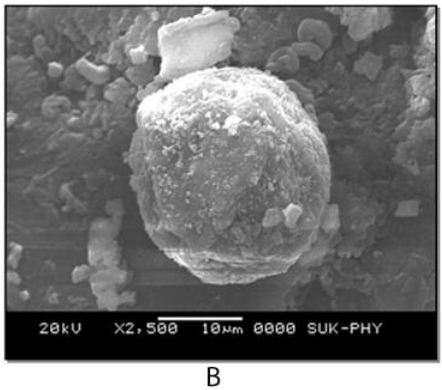

B
Fig. 3: SEM analysis of chitosan microspheres. Surface morphology of blank microsphere (A), surface morphology of drug loaded microsphere (B).

The percentage yield of formulated microspheres was 60 $82 \%$ (table 2). The particle size of the microspheres was found in the range of 29.1-52.65 $\mu \mathrm{m}$. Particle size of microspheres showed inverse relation with the stirring speed. It was found that increasing the speed up to $2200 \mathrm{rpm}$ resulted in decline in particle size and number of spherical particles. Clumping of particles and large size particles were observed at lower stirring speed of 1700 rpm. In present study, stirring speed was optimized to $2000 \mathrm{rpm}$ to obtain the microspheres in the range of 25-55 $\mu \mathrm{m}$.

An increase in the concentration of drug increased the particle size which may be attributed to increase in the viscosity of the droplets formed during emulsification, which may have caused an increase in the interfacial tension. A significant increase in the particle size $(P<0.05)$ observed with increase in polymer concentration may be due to the fact that increase in the concentration of polymer increases the crosslinking and hence the matrix density of microspheres further resulting into increase in particle size (Patil and Murthy, 2006). However, the concentration of crosslinking agent $(\mathrm{NaOH})$ did not affect the particle size.

\section{Percentage drug encapsulation}

The percentage drug encapsulation was found to be directly proportional to polymer and drug loading. The significant $(P<0.05)$ increase in the drug encapsulation with increase in drug loading may be due to increase in the drug concentration in polymer solution. Similar behavior with an increase in the polymer concentration can be due to increased viscosity, which results in the formation of larger microspheres, thus increasing the drug encapsulation significantly $(P<0.05)$ (Dubey and Parikh, 2004; Mali et al., 2010). As the concentration of crosslinking agent increases, there is marginal decrease in the drug encapsulation. The percent drug encapsulation was found to be in the range of $11.02-32.45 \%$ (table 2). 
Table 2: Physical characteristics of prepared ORDZ-loaded chitosan microspheres.

\begin{tabular}{|c|c|c|c|c|c|}
\hline Batch code & $\begin{array}{l}\text { Percent yield } \\
(\% \mathrm{w} / \mathrm{w})\end{array}$ & $\begin{array}{c}\text { Particle } \\
\text { size }(\mu \mathrm{m}) \\
\left(\text { mean }^{*} \pm \mathrm{SD}\right)\end{array}$ & $\begin{array}{c}\text { Percent drug } \\
\text { encapsulation } \\
(\% \text { w/w* } \pm \text { SD })\end{array}$ & $\begin{array}{c}\text { Percent Equilibrium } \\
\text { Swelling }\left(\mathbf{E}_{\mathrm{sw}}\right) \\
(\% * \pm \mathrm{SD})\end{array}$ & $\begin{array}{c}\text { Percent in vitro } \\
\text { bioadhesion } \\
(\% * \pm \text { SD })\end{array}$ \\
\hline A1 & 81.96 & $29.1 \pm 1.3$ & $13.38 \pm 0.18$ & $73.53 \pm 0.55$ & $73.86 \pm 4.27$ \\
\hline $\mathrm{A} 2$ & 68.41 & $35.46 \pm 0.56$ & $23.99 \pm 0.56$ & $68.33 \pm 0.81$ & $69.06 \pm 1.66$ \\
\hline A3 & 60.68 & $43 \pm 0.98$ & $32.45 \pm 0.62$ & $63.06 \pm 1.35$ & $65.46 \pm 2.66$ \\
\hline B1 & 74.93 & $51.35 \pm 0.75$ & $17.07 \pm 0.19$ & $74.43 \pm 0.72$ & $81.46 \pm 2.75$ \\
\hline $\mathrm{B} 2$ & 71.57 & $52.65 \pm 0.30$ & $18.48 \pm 0.95$ & $76.4 \pm 0.7$ & $85.73 \pm 3.40$ \\
\hline $\mathrm{C} 1$ & 79.04 & $38.9 \pm 0.5$ & $12.56 \pm 0.54$ & $73.06 \pm 0.60$ & $72.13 \pm 1.28$ \\
\hline $\mathrm{C} 2$ & 74.90 & $39.16 \pm 0.68$ & $11.02 \pm 0.98$ & $72.43 \pm 0.85$ & $69.33 \pm 2.11$ \\
\hline
\end{tabular}

* Mean of three readings, SD- Standard deviation.

\section{Percent equilibrium swelling and bioadhesion}

Estimation of percent equilibrium swelling $\left(\mathrm{E}_{\mathrm{sw}}\right)$ revealed the swelling behavior of microspheres (table 2). The increase in the drug concentration caused decrease in the $\mathrm{E}_{\mathrm{sw}}$ significantly $(P<0.05)$. This may be due to increase in the drug concentration with respect to the polymer concentration. On other hand, increase in the polymer concentration led to significant $(P<0.05)$ increase in $\mathrm{E}_{\mathrm{sw}}$, which may be because of swelling property of chitosan. The increase in the concentration of crosslinking agent caused negligible decrease in the $\mathrm{E}_{\mathrm{sw}}$. Low $\mathrm{E}_{\mathrm{sw}}$ values on increasing the concentration of crosslinking agent may be due to introduction of numerous cross-links in the hydrogel structure (Hamdi and Ponchel, 1999). The microspheres showed bioadhesion in the range of $65.46-85.73 \%$. The percent in vitro bioadhesion showed significant increase $(P<0.05)$ with increase in polymer concentration. This may be due to availability of more polymer chains for entanglement with the mucus. However, addition of drug in microspheres as well as increase in concentration of crosslinking agent $(\mathrm{NaOH})$ decreased its bioadhesive property due to reduction in number of polymer chains available for entanglement with the mucus (batch A1, C1, C2).

\section{In vitro drug release}

The in vitro drug release profile of ORDZ from microspheres is shown in figure 4,5 and 6 . The formulations exhibited slow release. The batches (A1, B1, B2, C1, C2) released almost $50 \%$ of drug within $48 \mathrm{~h}$ except the batches A2 and A3.

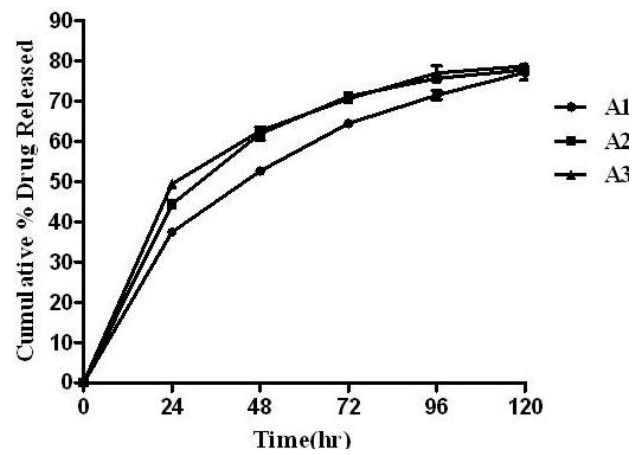

Fig. 4: In-vitro release profile of ORDZ in IPBS, pH 7.2 from chitosan microspheres containing different concentrations of drug.

The microspheres from batch $\mathrm{B} 1, \mathrm{~B} 2, \mathrm{C} 1$ and $\mathrm{C} 2$ extended the release up to $120 \mathrm{~h}$ (figure 4). As the amount of drug was increased from $0.8 \mathrm{gm}$ to $2.4 \mathrm{gm}$ (batch A1, A2 and A3) the rate and extent of release was found to be increased. A decrease in the rate and extent of drug release was observed with the increase in polymer concentration in microspheres of batch A1, B1 and B2 (figure 5).

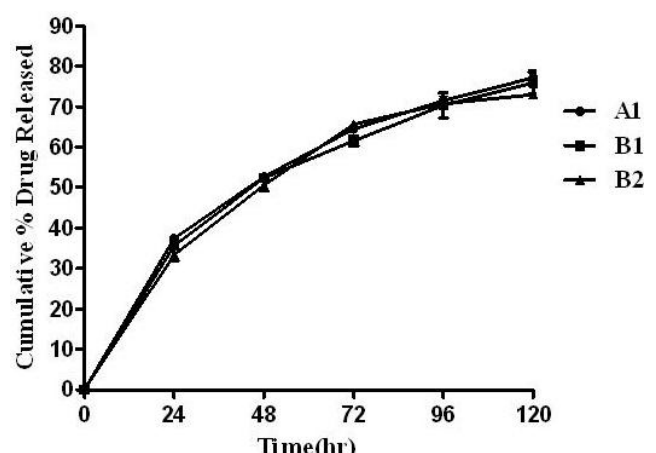

Fig. 5: In-vitro release profile of ORDZ in IPBS, pH 7.2 from chitosan microspheres containing different concentrations of chitosan.

This can be attributed to an increase in the density of polymer matrix and the diffusional path length that the drug has to traverse. The initial rapid release was reduced with an increase in polymer concentration which can be due to decrease in the amount of surface-associated drug with increase in the encapsulation efficiency. Further it was observed that the rate and extent of drug release was decreased with increase in concentration of sodium hydroxide (figure 6). This may be due to increased crosslinking of polymer which forms more compact structure resulting in less diffusion of drug from microspheres.

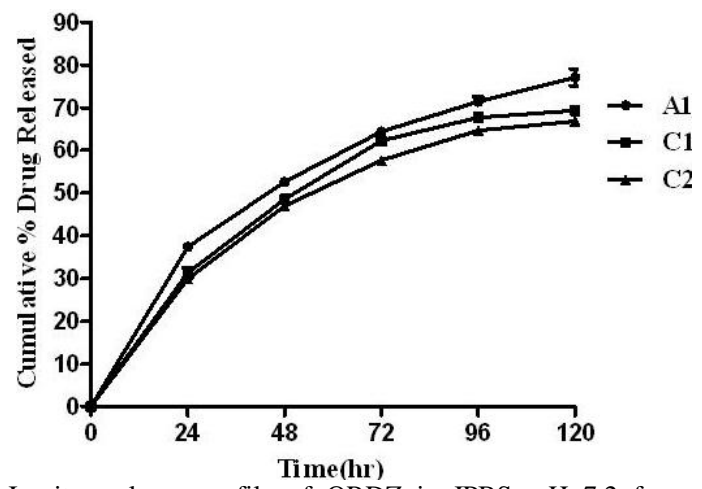

Fig. 6: In-vitro release profile of ORDZ in IPBS, pH 7.2 from chitosan microspheres containing different concentrations of sodium hydroxide. 
The drug release kinetics and mechanism were examined by fitting the release data into the models representing zero-order, first-order and Higuchi's square root of time. The linear regression analysis is summarized in table 3 . The coefficient of determination $\left(\mathrm{R}^{2}\right)$ values were much closer to 1 for the Higuchi kinetics, thus indicating that drug release from the microspheres followed diffusion controlled mechanism.

Table 3: Kinetics of in vitro ORDZ release from drug loaded chitosan microspheres.

\begin{tabular}{ccccccc}
\hline \multirow{2}{*}{$\begin{array}{c}\text { Batch } \\
\text { code }\end{array}$} & \multicolumn{2}{c}{ Zero order } & \multicolumn{2}{c}{ First order } & \multicolumn{2}{c}{ Higuchi } \\
\cline { 2 - 7 }$\left(\mathbf{m} \mathbf{~ h ~ h}^{\mathbf{- 1}}\right)$ & $\mathbf{R}$ & $\begin{array}{c}\mathbf{k} \\
\left(\mathbf{h}^{-\mathbf{1}}\right)\end{array}$ & $\mathbf{R}$ & $\begin{array}{c}\mathbf{K} \\
\left(\mathbf{m g ~ h} \mathbf{~ h}^{\mathbf{1} / 2}\right)\end{array}$ & $\mathbf{R}$ \\
\hline A1 & 0.00595 & 0.936 & -0.0119 & -0.989 & 0.0716 & 0.936 \\
A2 & 0.00586 & 0.887 & -0.0123 & -0.958 & 0.0733 & 0.887 \\
A3 & 0.00576 & 0.873 & -0.0123 & -0.956 & 0.0730 & 0.978 \\
B1 & 0.00586 & 0.940 & -0.0115 & -0.990 & 0.0704 & 0.998 \\
B2 & 0.00585 & 0.933 & -0.0112 & -0.976 & 0.0704 & 0.993 \\
C1 & 0.00559 & 0.933 & -0.0101 & -0.973 & 0.0672 & 0.992 \\
C2 & 0.00535 & 0.937 & -0.0093 & -0.977 & 0.0641 & 0.995 \\
\hline
\end{tabular}

$\mathrm{k}$ - release rate constant, $\mathrm{R}$ - coefficient of correlation.

To understand the mechanism of diffusion controlled release of ORDZ from microspheres, the results were further analysed according to equation (Sankar and Mishra, 2003)

$$
\mathrm{Q}(\mathrm{t})=\mathrm{at} \mathrm{t}^{\mathrm{n}}
$$

Where $\mathrm{Q}(\mathrm{t})$ is the fraction of drug released after time $\mathrm{t}$ and a denotes a coefficient, $\mathrm{n}$ is a release exponent. When $\mathrm{n} \leq 0.5$, this indicates a quasi-Fickian diffusion mechanism, for $\mathrm{n}>0.5$, an anomalous non-Fickian solute diffusion is observed, where as $\mathrm{n}=$ 1 indicates zero-order kinetics. Values of $\mathrm{a}$ and $\mathrm{n}$ are listed in table 4 . The values of $n$ were in the range of $0.29-0.51$, which is further indication of the diffusion controlled drug release.

Table 4: Coefficient and exponent of ORDZ release from drug-loaded chitosan microspheres

\begin{tabular}{cccc}
\hline Batch code & $\begin{array}{c}\text { Equation } \\
\text { coefficient (a) }\end{array}$ & $\begin{array}{c}\text { Release } \\
\text { exponent (n) }\end{array}$ & $\mathbf{R}^{\mathbf{2}}$ \\
\hline A1 & 1.59 & 0.45 & 0.997 \\
A2 & 1.17 & 0.35 & 0.980 \\
A3 & 1.28 & 0.29 & 0.994 \\
B1 & 0.91 & 0.47 & 0.996 \\
B2 & 0.84 & 0.50 & 0.983 \\
C1 & 0.80 & 0.51 & 0.982 \\
C2 & 0.78 & 0.51 & 0.986 \\
\hline
\end{tabular}

$\mathrm{R}^{2}-$ Coefficient of determination

Batch B2 exhibited optimum particle size $52.65 \mu \mathrm{m}$, $85.73 \pm 3.40 \%$ bioadhesion and extended release of drug for 120 h. The smaller size of the microspheres is not preferable as the smaller microspheres less than $50 \mu \mathrm{m}$ diameter can be removed from the periodontal pocket due to a high flow rate of gingival fluid $\left(20 \mu \mathrm{h} \mathrm{h}^{-1}\right)$ (Park et al., 2005). Therefore, batch B2 was taken as optimized formulation for further studies.

\section{In vitro antimicrobial activity}

The concentration of the drug in the samples remained well above the minimum inhibitory concentration $(0.8 \mu \mathrm{g} / \mathrm{ml})$ of the drug for a period of $120 \mathrm{~h}$ (figure 7). After $24 \mathrm{~h}$, pure drug showed the maximum zone of inhibition $(27.15 \mathrm{~mm})$. We found that the medium containing blank chitosan microspheres lacked antimicrobial activity. This may be due to the absence of ORDZ within the microspheres and insolubility of chitosan at $\mathrm{pH} 7.2$. The in vitro antimicrobial activity demonstrated satisfactory antimicrobial profile for all the microspheres against microorganism i.e. (Staphylococcus aureus).

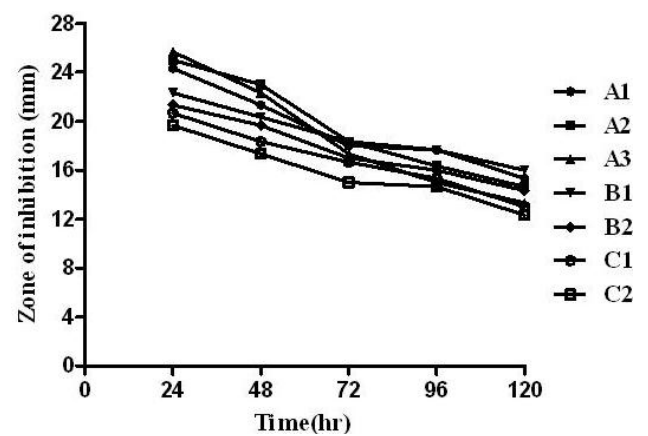

Fig. 7: In vitro antimicrobial activity of microspheres containing ORDZ.

\section{Characterization of in-situ gel containing ORDZ microspheres} Optimization of concentration of PF-127

Gelation temperature of plain PF-127 gels was observed for the concentration range of $16-20 \% \mathrm{w} / \mathrm{w}$ of PF-127 and it was found that gelation temperature of plain PF-127 gels decreased with increasing concentration of PF-127. When specified quantity of optimized formulation of microspheres based on the dose of ORDZ was added into PF-127 gels, the gelation temperature of formulation was found to be decreased significantly $(P<0.05)$. It was found that only $17 \%$ of PF-127 gel with optimized formulation of microspheres showed ability to form gel in the range of 25 to $32^{\circ} \mathrm{C}$ (table 5). Thus, $17 \%$ w/w concentration of PF127 was used for further studies.

Table 5: Gelation temperature of poloxamer solutions (16-20\% w/w)

\begin{tabular}{lcc}
\hline \multirow{2}{*}{ Composition } & \multicolumn{2}{c}{ Gelation Temperature $\left({ }^{0} \mathbf{C}\right)$} \\
\cline { 2 - 3 } & Mean & S.D. \\
\hline PF-127 (16\%) & 43.3 & 0.45 \\
PF-127 (16\%) + Optimized formulation & 39.43 & 0.64 \\
PF-127 (17\%) & 31 & 0.62 \\
PF-127 (17\%) + Optimized formulation & 27.9 & 0.45 \\
PF-127 (18\%) & 24.03 & 0.77 \\
PF-127 (18\%) + Optimized formulation & 20.93 & 1.00 \\
PF-127 (19\%) & 23.66 & 0.90 \\
PF-127 (19\%) + Optimized formulation & 19.56 & 0.70 \\
PF-127 (20\%) & 22.3 & 0.55 \\
PF-127 (20\%) + Optimized formulation & 18.93 & 0.68 \\
\hline
\end{tabular}

PF-127- Pluronic flake 127.

PF-127 was selected due to its thermogelling property. In addition to this, it exhibited desirable gelation temperature range $\left(25\right.$ to $32^{\circ} \mathrm{C}$ ) in comparison to PF-188.

\section{Gelation temperature}

Gelation temperature for optimized plain PF-127 solution was observed at $30.36^{\circ} \mathrm{C}$. When optimized formulation (batch B2) 
of ORDZ microspheres was added into PF-127 gel, it was found that gelation temperature of formulation decreased (table 6).

\section{Surface $p H$}

Surface $\mathrm{pH}$ of plain gel and the gel with optimized formulation was found in the range of 5.9 to 6.2 which was nearer to the oral $\mathrm{pH}$. It suggests prepared formulations having $\mathrm{pH}$ near to neutral $\mathrm{pH}$ and could improve the biocompatibility (table 6).

Table 6: Gelation temperature, surface $\mathrm{pH}$, in-vitro bioadhesive force of plain and microspheres containing gel.

\begin{tabular}{|c|c|c|c|}
\hline $\begin{array}{c}\text { Formulation } \\
\text { Code }\end{array}$ & $\begin{array}{c}\text { Gelation } \\
\text { temperature }\left({ }^{\circ} \mathrm{C}\right) \\
(\text { Mean } \pm \text { SD })\end{array}$ & $\begin{array}{l}\text { Surface pH } \\
(\text { Mean } \pm \text { SD })\end{array}$ & 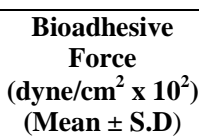 \\
\hline Plain gel & $31 \pm 0.62$ & $6.2 \pm 0.1$ & $49.04 \pm 1.68$ \\
\hline $\begin{array}{l}\text { Optimized } \\
\text { formulation }\end{array}$ & $27.9 \pm 0.45$ & $5.96 \pm 0.20$ & $75.15 \pm 3.82$ \\
\hline
\end{tabular}

\section{Viscosity measurement}

The plots of viscosity versus temperature studies of plain PF-127 gel and gel containing optimized ORDZ microspheres are shown in figure 8 . There was no considerable change in viscosity up to the point of gelation temperature. Near the point of gelation temperature the viscosity was found to be increased, followed by sudden increase in viscosity at transition temperature. It was found that gel containing optimized ORDZ microspheres remained in liquid state at room temperature and converted into gel at oral physiological temperature.

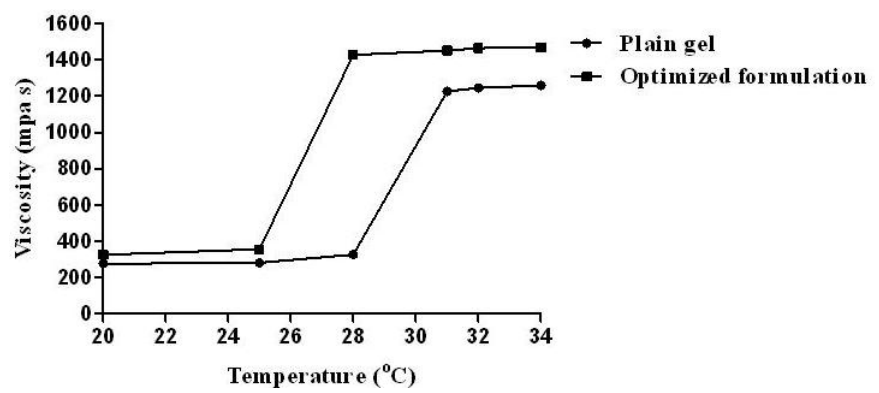

Fig. 8: Effect of temperature on viscosity of plain PF-127 gel and gel containing optimized ORDZ microspheres

\section{Determination of bioadhesive force}

Bioadhesive force of plain gel and gel containing optimized formulation was found to be $49.04 \times 10^{2}$ and $75.15 \mathrm{x}$ $10^{2}$ dyne $/ \mathrm{cm}^{2}$ respectively (table 6). Addition of microspheres containing bioadhesive polymer (chitosan) into the gel produced further increase in the bioadhesive force. This may be due to interactions between the positively charged amino groups of chitosan and the negatively charged mucosa resulting into strong bonding.

\section{In vitro drug release}

In-vitro release studies were carried out by process containing donor compartment and receptor compartment using IPBS, $\mathrm{pH}$ 7.2. It was observed that the release rate of ORDZ was controlled for a period of 7 days (figure 9). This may be attributed to combined effect of viscous nature of gel that increased contact period and prolongation of drug release due to chitosan microspheres.

The drug release kinetics and mechanism was examined by fitting the release data into the models representing zero-order, first-order and Higuchi's square root of time. The linear regression analyses are summarized in table 7 . The coefficient of correlation $\left(\mathrm{R}^{2}\right)$ value was much closer to 1 for the Higuchi kinetics, thus indicating that drug release from the microspheres followed diffusion controlled mechanism. The data obtained was further analysed for ' $n$ ' values (table 8). The value of $n$ was 0.57 , indicating that the mechanism of drug release was diffusion controlled.

Table 7: Kinetics of in vitro ORDZ release from gel containing optimized chitosan microspheres.

\begin{tabular}{|c|c|c|c|c|c|c|}
\hline \multirow[b]{2}{*}{ Batch code } & \multicolumn{2}{|c|}{ Zero order } & \multicolumn{2}{|c|}{ First order } & \multicolumn{2}{|l|}{ Higuchi } \\
\hline & $\begin{array}{l}\mathbf{k} \\
\left(\mathrm{mg} \mathrm{h}^{-1}\right)\end{array}$ & $\mathbf{R}$ & $\begin{array}{l}\mathbf{k} \\
\left(\mathbf{h}^{-1}\right)\end{array}$ & $\mathbf{R}$ & $\begin{array}{l}\mathbf{k} \\
\left(\mathrm{mg} \mathrm{h}^{-1 / 2}\right)\end{array}$ & $\mathbf{R}$ \\
\hline $\begin{array}{l}\text { Optimized } \\
\text { formulation }\end{array}$ & 0.0043 & 0.948 & -0.0087 & -0.990 & 0.062 & 0.995 \\
\hline
\end{tabular}

Table 8. Coefficient and exponent of ORDZ release from gel containing optimized chitosan microspheres

\begin{tabular}{cccc}
\hline Batch code & $\begin{array}{c}\text { Equation } \\
\text { coefficient (a) }\end{array}$ & $\begin{array}{c}\text { Release } \\
\text { exponent (n) }\end{array}$ & $\mathbf{R}^{\mathbf{2}}$ \\
\hline Optimized formulation & 1.43 & 0.57 & 0.991 \\
\hline
\end{tabular}

$\mathrm{R}^{2}-$ Coefficient of determination.

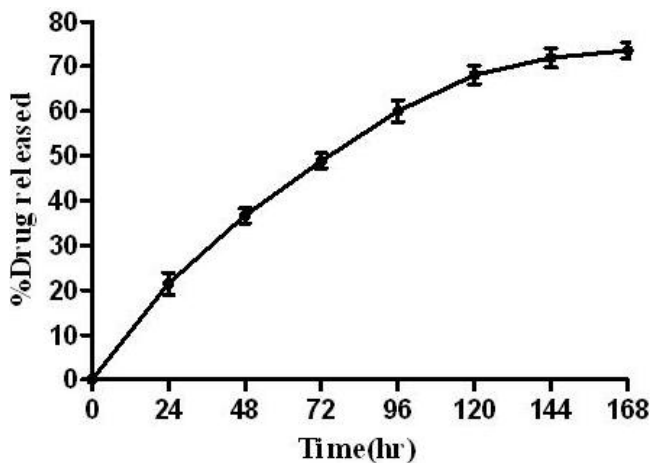

Fig. 9: In-vitro release study of gel containing optimized ORDZ microspheres in IPBS, $\mathrm{pH}$ 7.2.

\section{CONCLUSION}

Microspheres containing ORDZ with appropriate physical features and drug content was successfully prepared by using chitosan which provided good bioadhesion of the microspheres as well as exhibited sustained release of drug. With the help of in situ gel, microspheres can be easily administered into periodontal pocket and release of drug can also be extended. The developed formulation may be proposed as a promising system for delivery of ORDZ for local treatment of periodontitis. It may help to achieve adequate drug concentration in periodontal pocket and control its release. Further, in vivo studies are required to confirm the efficacy of the formulation. 


\section{ACKNOWLEDGEMENT}

The authors are grateful to Prof. D. B. Sagare, Founder President, Yashoda Technical Campus, Satara for providing research facilities.

Financial support and sponsorship: Nil.

Conflict of Interests: There are no conflicts of interest.

\section{REFERENCES}

Asane GS, Rao YM, Bhatt JH, Shaikh KS. Optimization, Characterisation and Pharmacokinetic Studies of Mucoadhesive Oral Multiple Unit Systems of Ornidazole. Sci Pharm, 2011; 79: 181-196.

Bottenberg P, Cleymaet R, Muynck CP. Development and testing of bioadhesive; fluoride containing slow release tablets for oral use. J Pharm Pharmacol, 1991; 43: 457-464.

Chandur VK, Mastiholimath VS, Hatapakki BC, Suresh HM, Shivakumar SI, Sianam SS. Site specific low cost ornidazole strip for long term treatment of periodontal disease. Indian J Pharm Educ Res, 2007;41:224-228.

Choi HG, Jung JH, Ryu IM, Yoon SJ, Oh YK, Kim CK. Development of in situ-gelling and mucoadhesive acetaminophen liquid suppository. Int J Pharm, 1998; 165:33-44.

Dias RJ, Ghorpade VS, Havaldar VD, Mali KK, Salunkhe NH, shinde JH. Development and optimization of interpenetrating network beads of Delonix regia gum and sodium alginate using response surface methodology. J App Pharm Sci, 2015;5(05):56-64.

Dubey RR, Parikh RH. Two stage optimization process for formulation of chitosan microsphere. AAPS PharmSciTech, 2004; 5:E 5 .

Friedman M, Steinberg D. 1988. Sustained release drug delivery devices for local treatment of dental diseases. In: Tyles P (ed) Drug delivery devices; fundamentals and application. New York: Marcel Dekker Inc. 492-515.

Goodson JM, Haffajee A, Socransky SS. Periodontal therapy by local delivery of tetracycline. J Clin Periodontol, 1979;6:83-92.

Govender S, Pillay V, Chetty DJ, Essack SY, Dangor CM, Govender T. Optimization and characterization of bioadhesive controlled release tetracycline microspheres. Int J Pharm, 2005;306:24-40.

Gulzar AMG, Charyulu RN, Harish NM, Prabhu P. Formulation and in-vitro evaluation of Chitosan films containing tetracycline for the treatment of periodontitis. Asian J Pharm, 2009; 3(2):113-119.

Haerdi-landerer MC, Suter MM, Steiner A, Wittenbrink MM, Pickl A, Gander BA. In vitro cell compatibility and antibacterial activity of microencapsulated doxycycline designed for improved localized therapy of septic arthritis. J Antimicrob Chemother, 2008; 61:332-340.

Hamdi G, Ponchel G. Enzymatic degradation of epichlorhydrin crosslinked starch microspheres by $\alpha$-amylase. Pharm Res, 1999;16:867875 .

Jain N, Jain GK, Javed S, Iqbal Z, Talegaonkar S, Ahmad FJ, et al. Recent approaches for the treatment of periodontitis. Drug Discov Today, 2008;13:932-43.

Kumar MN, Muzzarelli RA, Muzzarelli C, Sashiwa H, Domb AJ. Chitosan chemistry and pharmaceutical perspectives. Chem Rev, 2004;104(12):6017-84.

Lim LY, Wan LSC, Thai PY. Chitosan microspheres prepared by emulsification and ionotropic gelation. Drug Dev Ind Pharm, 1997;23:981-985.

Mali KK, Dias RJ, Ghorpade VS, Havaldar VD. Sodium alginate microspheres containing multicomponent inclusion complex of domperidone. Lat Am J Pharm, 2010;29:1199-1207.

Mastiholimath VS, Dandagi PM, Gadad AP, Patil MB, Manvi FV, Chandur VK. Formulation and evaluation of ornidazole dental implants for periodontitis. Indian J Pharm Sci, 2006, 68 (1): 68-71.
Mi FL, Tseng YC, Chen CT, Shyu SS. Preparation and release properties of biodegradable chitin microcapsules. II. Sustained release of 6-mercaptopurine from chitin microcapsules. J Microencapsul, 1997;14:211-223

Nair R, Reddy BH, Ashok Kumar CK, Kumar KJ. Application of chitosan microspheres as drug carriers: A review. J Pharm Sci \& Res, 2009;1:1-12.

Neil MJ, Smith A, Heckelman PE. 2006. The Merck Index. $14^{\text {th }}$ ed. NJ:Merck Research Laboratories.

Papageorgiou GZ, Papadimitriou S, Karavas E, Georgarakis E, Docoslis A, Bikiaris D. Improvement in chemical and physical stability of fluvastatin drug through hydrogen bonding interactions with different polymer matrices. Curr Drug Del, 2009;6:101-112.

Park YJ, Lee JY, Yeom HR, Kim KH, Lee SC, Shim IK, et al. Injectable polysaccharide microcapsules for prolonged release of minocycline for the treatment of periodontitis. Biotechnol Lett, 2005;27:1761-1766.

Park YJ, Yong CS, Kim HM, Rhee JD, Oh YK, Kim CK et al. Effect of sodium chloride on the release; absorption and safety of diclofenac sodium delivered by poloxamer gel. Int $\mathrm{J}$ Pharm, 2003;263:105-111.

Patel B, Shah S, Kumar S. Evaluation of Ornidazole Gel as an Adjunct to the Phase I Therapy. Adv Hum Biol, 2014;4(3):21-25.

Patel DM, Soneji JA, Patel PB, Patel CN. Development and validation of a method for simultaneous estimation of ofloxacin and ornidazole in different dissolution media. Pharm Methods, 2012;3(2): $102-105$.

Patil SB, Murthy SR. Preparation and in vitro evaluation of mucoadhesive chitosan microspheres of amlodipine besylate for nasal administration. Indian J Pharm Sci, 2006;68:64-77.

Patil V, Mali R, Mali A. Systemic anti-microbial agents used in periodontal therapy. J Indian Soc Periodontol, 2013 ;17(2): 162-168.

Pichayakorn W, Boonme P. Evaluation of cross-linked chitosan microparticles containing metronidazole for periodontitis treatment. Mater Sci Eng C Mater Biol Appl, 2013;33(3):1197-202.

Piñón-Segundo E, Ganem-Quintanar A, Alonso-Pérez V, Quintanar-Guerrero D. Preparation and characterization of triclosan nanoparticles for periodontal treatment. Int J Pharm, 2005 27;294(12):217-32.

Rahman S, Ahija A, Ali J, Khar RK. Site specific delivery systems for the treatment of periodontitis. Indian J Pharm Sci, 2003;65: 106-112.

Rajashree MS, Shukla AV, Vashudha M, Bolmal UB, Manvi FV. Development and characterization of ornidazole gels using natural polymers for local treatment of periodontitis. Indian drugs, 2009;46:.25 31.

Ranga Rao KV and Buri PA. A novel in situ method to test polymers and coated microparticles for bioadhesion. Int J Pharm, 1989;52:265-270.

Sachdeva S, Agarwal V. Evaluation of commercially available biodegradable tetracycline fiber therapy in chronic periodontitis. J Indian Soc Periodontol, 2011;15(2): 130-134.

Saini S, Gipta N, Mahajan AM, Arora DR. Micobial flora in orodental infections. Ind. J. Med. Microbiol, 2003;21: 111-114.

Sankar C, Mishra B. Development and in vitro evaluation of gelatin A microspheres of ketorolac tromethamine for intranasal administration. Acta Pharm, 2003; 53:101-110.

Schmolka IR. Artificial Skin I: Preparation and properties of Pluronic-127 gels for treatment of burns. J Biomed Mater Res, 1972;6:571-582.

Sinko PJ and Sing Y. 1996. Martin's Physical pharmacy and Pharmaceutical Sciences. $6^{\text {th }}$ ed. Baltimore: Lippincott Williams \& Wilkins.

Suresh PK, Dewangan MK. Development and in vitro characterization of metronidazole loaded chitosan microspheres for delivery to periodontal pocket. J of App Pharm Sci, 01 (08); 2011: 165 169. 
Swamy NGN, Abbas Z, Praveen B. Fabrication and In vitro Evaluation of Doxycycline Loaded Chitosan Microspheres for the Treatment of Periodontitis. RGUHS J Pharm Sci, 2013;3(2):26-32.

Sweetman SC. 2005. Martindale: The complete drug reference. $34^{\text {th }}$ ed. London: Pharmaceutical Press.

Tariq M, Iqbal Z, Ali J, Baboota S, Talegaonkar S, Ahmad Z, Sahni JK.Treatment modalities and evaluation models for periodontitis. Int J Pharm Investig. 2012; 2(3): 106-122.

Vyas SP, Sihorkar V, Dubey PK.Preparation, characterization and in vitro antimicrobial activity of metronidazole bearing lectinized liposomes for intra-periodontal pocket delivery. Pharmazie, 2001; 56(7):554-60.

Yadav AV, Mote HH. Development of biodegradable starch microspheres for intranasal delivery. Indian J Pharm Sci, 2008;70:170174.

\section{How to cite this article:}

Dias RJ, Havaldar VD, Ghorpade VS, Mali KK, Gaikwad VK, Kumbhar DM. Development and Evaluation of In-Situ Gel Containing Ornidazole Loaded Microspheres for Treatment of Periodontitis. J App Pharm Sci, 2016; 6 (10): 200-209. 